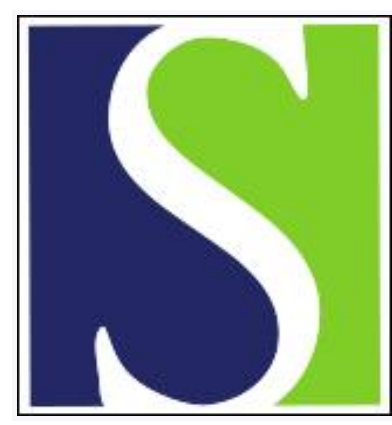

Scand J Work Environ Health 1999;25(4):335-341

https://doi.org/10.5271/sjweh.443

Issue date: Aug 1999

Asthma in tunnel workers exposed to synthetic resins

by Ulvestad B, Melbostad E, Fuglerud P

The following article refers to this text: 2001;27(4):217-218

Key terms: isocyanates; methacholine responsiveness

This article in PubMed: www.ncbi.nlm.nih.gov/pubmed/10505659

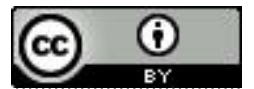




\title{
Asthma in tunnel workers exposed to synthetic resins
}

\author{
by Bente Ulvestad, MD, ${ }^{1}$ Erik Melbostad, MD, ${ }^{+}$Per Fuglerud, $M S c^{2}$
}

\author{
Ulvestad B, Melbostad E, Fuglerud P. Asthma in tunnel workers exposed to synthetic resins. Scand J Work \\ Environ Health 1999;25(4):335-341.
}

\begin{abstract}
Objectives The prevalence of asthma among tunnel workers exposed to synthetic resins was studied by determining airway symptoms, methacholine responsiveness, and lung function.

Methods Nineteen injection workers were compared with a group of 104 other tunnel workers with similar exposure, except for that to synthetic resins. A questionnaire on respiratory symptoms, smoking habits, use of respiratory protection, and work tasks was used. Lung function was studied using a bellows spirometer. Bronchial reactivity was tested with methacholine. Allergy screening with Phadiatop and radioallergosorbent tests for toluene-diisocyanate-HSA, diphenylmethane-4.4-diisocyanate-HSA, and formaldehyde-HSA (HSA = human serum albumin) were carried out. Methylene diphenyl diisocyanate (MDI) and MDI prepolymer exposure was estimated by filter sampling, and the filters were analyzed by high-performance liquid chromatography. The most common work situations were simulated for an estimation of exposure to isocyanates.

Results The injection workers reported more respiratory symptoms than the reference group, and they had higher prevalences of bronchial hyperresponsiveness ( $37 \%$ versus $14 \%$ ), asthma ( $26 \%$ versus $1 \%$ ), and airflow limitation (37\% versus 4\%). Toluene-diisocyanate-HSA-specific immunoglobulin $\mathrm{E}$ antibodies were found in 2 of the 19 injection workers, but in none of the other tunnel workers. By simulation at a worksite, the average exposure to polymerized MDI was estimated to be $5.5-300 \mu \mathrm{g} / \mathrm{m}^{3}$ during injection work and $18-4300 \mu \mathrm{g} / \mathrm{m}^{3}$ during shortterm exposure, the highest exposure occurring when cured polyurethane was ground.

Conclusions Exposure to partly decomposed MDI in tunnel work enhances the risk for respiratory symptoms, methacholine hyperresponsiveness, asthma, and airflow limitation.
\end{abstract}

Key terms isocyanates, methacholine responsiveness.

Respiratory hazards vary among construction workers from the well-recognized effects of asbestos and silica to more recently described respiratory diseases caused by exposure to isocyanates (1) and epoxy compounds (2). In a previous investigation, we found that exposures in tunnel excavation enhance the risk of respiratory symptoms and airway obstruction among tunnel workers when compared with that of other heavy construction workers (3). Sealing and rock consolidation work sometimes requires that large amounts of acrylamide grouting resins or polyurethane foam be injected into the rock to prevent water leakage. In such cases, isocyanates and amines could be expected to evaporate during the curing process. Whether or not such evaporation occurs depends upon the type of grouting resin used (4).

Occupational asthma in relation to exposure to isocyanates was reported as early as 1951, and such exposure has been shown to occur during the handling of polyurethane foam (4). Isocyanates are regarded as one of the main causes of occupational asthma, and the large number of workers exposed to these chemicals has a concentration-dependent risk of developing chronic airway disorders $(1,5,6)$. Hypersensitivity pneumonitis, rhinoconjunctivitis, and fever induced by diphenylmethane diisocyanate have been reported $(7,8)$. Specific immunoglobulin $\mathrm{E}(\mathrm{IgE})$ mediated sensitization and irritative effects have been found among exposed humans and animals (9). Exposure to acrylamide resins has mainly been described as due to the inhalation of component powders or fumes liberated when resins are converted to hard solids by the addition of curing agents or hardeners $(10,11)$. Occupational asthma in relation to exposure to synthetic resins has, as far as we know, not been reported for tunnel workers.

Nonspecific bronchial challenge has been suggested as a more objective method than questionnaires to assess

1 National Institute of Occupational Health, Oslo, Norway.

$\dagger \quad$ Deceased (March 11 1999).

2 Parexel Medstat Research, Lillestrøm, Norway.

Reprint requests to: Dr Bente Ulvestad, Selmer ASA, Pb 1175 Sentrum, 0107 Oslo, Norway. [E-mail: bente.ulvestad@ selmer.no] 
the prevalence of asthma-related conditions in epidemiologic surveys (12-14).

In the present study we wanted to explore the hypothesis that injection workers may be at increased risk of developing respiratory impairment due to exposure from work with synthetic resins. Our aim therefore was to investigate the prevalence of airway symptoms, methacholine responsiveness, and obstructive lung disease among injection workers and referents comprised of other tunnel workers not exposed to synthetic resins but otherwise similarly exposed.

We also wanted to simulate common exposure situations for the injection workers and carry out an exposure assessment for the most common polyurethanes that had been used.

\section{Subjects and methods}

A cross-sectional study comprising injection workers who had been exposed to polyurethane and acrylic resins $(\mathrm{N}=19)$, and a reference group of other tunnelface workers $(\mathrm{N}=104)$ not exposed to polyurethane or acrylamide, was established. The reference group is hereafter referred to as tunnel workers.

The injection workers were previous tunnel workers who were later grouped into a department set up for sealing work. All the workers employed in this department in 1996 were included. The tunnel workers in the reference group worked at 6 different sites. The participation rate was $100 \%$ in both groups. Demographic data are given in table 1.

The prevalence of current smoking was $58 \%$ for the injection workers and $54 \%$ for the tunnel workers. There was an even distribution of current smokers across the age groups. Duration of smoking was 24 (SD 12.1) years (arithmetic mean) for the smoking injection workers and 20 (SD 8.0) years (arithmetic mean) for the smoking tunnel workers.

\section{Questionnaire}

A self-administered questionnaire (modified version of the one developed by the Medical Research Council in the United Kingdom) was answered before the medical testing. Respiratory symptoms in general (dyspnea, wheezing and cough), work-related symptoms, presence of allergy or asthma in the family, asthma prior to construction employment, allergy, infections of the respiratory system (last time and when), use of airway protection, and smoking habits were recorded.

A structured interview was carried out to clarify the use of injection chemicals. The workers were asked to name the chemicals, explain how frequently and in what way they were used, and describe the information they had been given about the chemicals and their possible hazards.

\section{Spirometry}

A bellows spirometer Vitalograph S with a PFT2 PLUS printer was applied according to ATS recommendations (15). Gulsvik's reference values from Oslo, Norway, were used (16). At least 2 identical curves or a minimum of 3 curves with a maximum deviation between the 2 best ones of $3 \%$ in forced volume capacity (FVC) and forced expiratory volume in 1 second $\left(\mathrm{FEV}_{1.0}\right)$ were required. The tests were done at the worksite.

\section{Methacholine provocation test}

Subjects whose baseline $\mathrm{FEV}_{1.0}$ was $\geq 60 \%$ of the predicted value had a methacholine challenge test. They were asked not to smoke during the 2 hours before their ap pointment for testing. The test was postponed for a minimum of 6 weeks after any infection of the respiratory system. The procedure for inhaling methacholine was carefully standardized using the Cockroft \& Hargreaves method (17). A Wright jet nebulizer and 2 minutes of inhalation were used. The starting concentration was 2 $\mathrm{mg} / \mathrm{ml}$. Unless the $\mathrm{FEV}_{1.0}$ decreased by $\geq 20 \%$ from one concentration to the next, a doubling of the concentration was given. $\mathrm{FEV}_{1.0}$ was measured 30 and 90 seconds after each dose. The challenge was stopped if a maximum concentration of $32 \mathrm{mg} / \mathrm{ml}$ was reached, or the $\mathrm{FEV}_{1.0}$ decreased by $\geq 20 \%$ from the baseline value. The stop concentration was defined as the $\mathrm{PC}_{20}$ value. The results were divided into the following categories: $\leq 8 \mathrm{mg}$ / $\mathrm{ml}$ (methacholine hyperresponsiveness), $>8-32 \mathrm{mg} / \mathrm{ml}$ (intermediate responsiveness), and $>32 \mathrm{mg} / \mathrm{ml}$ (normal responsiveness).

A methacholine inhalation test was not undertaken for subjects whose $\mathrm{FEV}_{1.0}$ was less than $60 \%$ of the predicted value. Instead salbutamol $(0.4 \mathrm{mg})$ inhalation was given as a reversibility test. Subjects with an increase of more than $15 \%$ in their $\mathrm{FEV}_{1.0}$ were considered to have increased bronchial responsiveness.

Table 1. Demographic data of the 19 injection workers and 104 tunnel workers included in the survey.

\begin{tabular}{|c|c|c|c|c|c|c|c|c|c|}
\hline & \multicolumn{3}{|c|}{ Age (years) } & \multicolumn{3}{|c|}{ Years in the same job } & \multicolumn{3}{|c|}{ Height $(\mathrm{cm})$} \\
\hline & Mean & SD & Range & Mean & SD & Range & Mean & $\mathrm{SD}$ & Range \\
\hline Injection workers & 46 & 14.6 & $20-67$ & 21 & 10.9 & $1-42$ & 179 & 5.6 & $167-194$ \\
\hline Tunnel workers & 39 & 8.8 & $18-67$ & 13 & 7.7 & $1-46$ & 179 & 6.0 & $167-194$ \\
\hline
\end{tabular}


Altogether 118 subjects were challenged with methacholine, and 5 subjects had a reversibility test instead.

\section{Immunoglobulin E measurements}

Each employee had a venous blood sample drawn. The serum samples were frozen at $-70^{\circ} \mathrm{C}$. IgE antibodies specific to human serum albumin (HSA) conjugated toluene-diisocyanate, diphenylmethane-4.4-diisocyanate, and formaldehyde were assessed by radioallergosorbent tests (RAST) (Pharmacia Diagnostics AB). Phadiatop (Pharmacia Diagnostics AB, Uppsala, Sweden), a multiple RAST of IgE against 8 common allergens, was used for screening for atopic allergy (18).

\section{Clinical examination}

A clinical examination was carried out to determine whether the subjects had obstructive lung disease (asthma or chronic obstructive lung disease). Diagnostic criteria applied in a previous Norwegian population survey (19) were used. Asthma was diagnosed for those with a history of attacks of shortness of breath at rest, and with wheezing in the chest changing in severity over short periods of time, either spontaneously or after treatment. At least 1 typical attack had to have occurred within the previous 6 months. Chronic obstructive lung disease was diagnosed for those with a history of chronic cough, phlegm when coughing, breathlessness or wheezing, or both and a ratio of $\mathrm{FEV}_{1.0}$ to FVC of less than 0.7 (20). Subjects with spirometric airflow limitation were defined as those with a ratio of $\mathrm{FEV}_{1.0}$ to $\mathrm{FVC}$ of less than 0.7 and $\mathrm{FEV}_{1.0}$ of less than $80 \%$ of the predicted value. The occupational exposure of the subjects was not known to the physician who performed the clinical examination.

\section{Exposure}

The "injection department" manager estimated that, during the last 10 years, the workers (altogether) had injected a total of about 260 metric tons of acrylic resins and 110 metric tons of polyurethane. Different polyurethanes had been used. In the early 1980 s the most commonly used flexible foam was derived from toluene-diisocyanate (TDI) (2), but because of its volatility, TDI has largely been replaced by the less volatile methylene diphenyl diisocyanate (MDI), which produces more rigid polyurethane foams.

Currently, polyurethane foams consisting of $10-30 \%$ diphenylmethane-4.4-diisocyanate, $10-30 \%$ diphenylmethane-4.4-diisocyanate prepolymers, and 30-60\% di$\mathrm{n}$-butylphthalate are the most common. The reactions are enhanced by the use of catalysts such as amines, and the resultant polymer is stabilized. The reaction requires only a few minutes. The acrylamide resins used consisted of $30-60 \%$ n-methylolacrylamide, $<2 \%$ acrylamide, and $1 \%$ formaldehyde.
No exposure measurements were available from the years the "injection department" had existed. We therefore wanted to simulate the most common exposure situations for the workers during the last 10 years. As we have found no evidence in the literature that exposure to acrylamide resins consisting of n-methylolacrylamide causes airway disease, the exposure assessment was carried out with the most common polyurethanes in use.

\section{Exposure assessment}

The strategy included personal and stationary sampling to estimate average and peak concentrations of isocyanates in the vapor and aerosol phases.

The workers and sampling locations were selected on the basis of the work operations, such as the injection process, the mixing of reactants, the cleaning of equipment, the grinding of hardened polyurethane, and the drilling of new holes. The sampling period varied from 5 minutes (peak monitoring) to 165 minutes (timeweighted average monitoring).

Samples were collected on filters impregnated with 1-2-methoxyphenyl piperazine with the use of SKC Aircheck sampling pumps. The flow rate was approximately $21 / \mathrm{min}$, which was measured with a calibrated flowmeter. Any organic isocyanates present react to form nonvolatile urea derivatives. The filters were analyzed by high-performance liquid chromatography with ultraviolet and electrochemical detection. Isocyanate-derived peaks were identified on the basis of their electrochemical or ultraviolet responses and quantified by comparison with the relevant isocyanate monomer standard. The total isocyanate air concentration was estimated from the sum of all the isocyanate-derived peaks (21). The analytical principle was the same for the isocyanates from prepolymers. The identification and quantification was confirmed by comparing retention times in a bulk sample of the process prepolymer and sample chromatograms.

\section{Statistical methods}

Relationships between binary (yes;no) response variables and the covariates work group, smoking status, and years employed in the same work were investigated by means of a logistic regression analysis (22). The covariate smoking status contained the categories never, former and current smoking and the covariate years employed in the same work were broken down into $<10$ years, $10-20$ years and $>20$ years. Age was not included in the model due to its high correlation with the covariate years employed in the same trade. The risk ratio between injection and tunnel workers was estimated by the adjusted odds ratio (injection;tunnel) from the regression model including all 3 covariates. Corresponding 95\% confidence intervals $(95 \% \mathrm{CI}$ ) for the adjusted odds ratios (OR) were also calculated with the use of the estimated 
coefficients and the standard errors from the regression models.

The lung function variables were presented as a percentage of the predicted value. The differences between the injection and tunnel workers were tested using a 3way analysis of variance model (23) with work group, smoking status, and years employed with the same work as the covariates in the model. The least square means and corresponding 95\% confidence intervals for the 2 work groups were also calculated.

The reduction in lung function as a function of the number of years employed in the same job was estimated by a simple linear regression (22). The reduction was estimated for each work group and stratified by smoking status.

\section{Results}

\section{Medical survey}

The injection workers reported significantly more workrelated respiratory symptoms than the tunnel workers (ta-

Table 2. Prevalence of respiratory symptoms among the injection $(\mathrm{N}=19)$ and tunnel $(\mathrm{N}=104)$ workers. $(95 \% \mathrm{Cl}=95 \%$ confidence interval)

\begin{tabular}{|c|c|c|c|c|}
\hline \multirow[t]{2}{*}{ Respiratory symptoms } & \multicolumn{2}{|c|}{$\begin{array}{l}\text { Symptom } \\
\text { prevalence }\end{array}$} & \multirow[t]{2}{*}{$\begin{array}{l}\text { Odds } \\
\text { ratio }^{\mathrm{a}}\end{array}$} & \multirow[t]{2}{*}{$95 \% \mathrm{Cl}$} \\
\hline & $\begin{array}{l}\text { Injection } \\
\text { workers } \\
\text { (N) }\end{array}$ & $\begin{array}{l}\text { Tunnel } \\
\text { workers } \\
\text { (N) }\end{array}$ & & \\
\hline Work-related cough and wheezing & 11 & 27 & 3.6 & $1.3-10.2$ \\
\hline Work-related tightness in the chest & 8 & 14 & 4.3 & $1.4-13.3$ \\
\hline Morning cough & 8 & 31 & 1.3 & $0.4-4.0$ \\
\hline Cough during the day & 10 & 17 & 5.1 & $1.7-15.2$ \\
\hline Daily cough more than 3 months & 7 & 5 & 10.6 & $2.8-39.6$ \\
\hline Dyspnea by effort & 11 & 25 & 4.0 & $1.4-11.6$ \\
\hline Attacks of dyspnea & 9 & 8 & 11.1 & $3.2-38.2$ \\
\hline Wheezing & 11 & 27 & 3.5 & $1.2-10.1$ \\
\hline
\end{tabular}

a Odds ratio adjusted for years in the same job and smoking status in a logistic regression analysis. ble 2). No significant association between work-related respiratory symptoms and the length of exposure (years in the same job) was found. The injection workers also reported significantly more respiratory symptoms in general than the tunnel workers (table 2). Dyspnea was associated with length of employment (OR 3.4, 95\% CI $1.1-11.3$, for $<10$ years versus $>20$ years $)$.

The prevalence of specific allergy, analyzed by Phadiatop, was $13 \%$ for both the injection workers and the tunnel workers. Allergy demonstrated by the Phadiatop test, reported allergy, or asthma in the family were unrelated to respiratory symptoms, lung function, or methacholine responsiveness and were not considered further as confounding factors.

The injection workers had reduced ventilatory lung function of an obstructive pattern when compared with the group of tunnel workers (table 3 ). The reduced $\mathrm{FEV}_{1.0}$ and $\mathrm{FEV} \mathrm{V}_{1.0}: \mathrm{FVC}$ ratio determined for the never smoking injection workers was shown to be associated with the length of exposure (years in the same job) in a linear regression model $(\mathrm{P}=0.03)$.

The injection workers had significantly higher bronchial hyperresponsiveness than the tunnel workers (OR $3.2,95 \%$ CI 1.1-9.7). Of the 19 "injection" workers tested, $7(37 \%)$ had a $\mathrm{PC}_{20}$ of $<8$, while $3(16 \%)$ were minor responders. Of the 104 heavy construction workers 15 $(14 \%)$ had a $\mathrm{PC}_{20}$ of $<8$, and $11(10.5 \%)$ were minor responders. Three of the injection workers and 2 of the tunnel workers had a $\mathrm{FEV}_{1.0}$ of less than $60 \%$ of the predicted value, and salbutamol inhalation was given as a reversibility test. None of these subjects had an increase of more than $15 \%$ in $\mathrm{FEV}_{1.0}$, and they were not considered to have increased bronchial responsiveness.

The estimated prevalence of asthma, chronic obstructive lung disease, and airflow limitation was significantly higher for the injection workers than for the tunnel workers (table 4). Cases with chronic obstructive lung disease were only found among the smokers. Spirometric airflow limitation was observed in 3 subjects with asthma and 4 subjects with chronic obstructive lung disease. In a logistic regression model, airflow limitation

Table 3. Lung function (percentage of predicted) of the injection $(\mathrm{N}=19)$ and the tunnel $(\mathrm{N}=104)$ workers. $(95 \% \mathrm{Cl}=95 \%$ confidence interval, $F V C=$ forced vital capacity, $\mathrm{FEV}_{1.0}=$ forced expiratory volume in 1 second, $\mathrm{FEF}_{25-75}=$ forced expiratory flow rate at $25-75 \%$ of the forced vital capacity)

\begin{tabular}{|c|c|c|c|c|c|c|c|c|}
\hline \multirow[t]{3}{*}{ Group } & \multicolumn{8}{|c|}{ Lung function, $\%$ of predicted } \\
\hline & \multicolumn{2}{|c|}{ FVC } & \multicolumn{2}{|c|}{$\mathrm{FEV}_{1}$} & \multicolumn{2}{|c|}{$\mathrm{FEV}_{1.0}: \mathrm{FVC}$} & \multicolumn{2}{|c|}{$\mathrm{FEF}_{25-75}$} \\
\hline & $\begin{array}{c}\text { Arithmetic } \\
\text { mean }^{\mathrm{a}}\end{array}$ & $95 \% \mathrm{Cla}^{\mathrm{a}}$ & $\begin{array}{c}\text { Arithmetic } \\
\text { mean }^{\mathrm{a}}\end{array}$ & $95 \% \mathrm{Cl}^{\mathrm{a}}$ & $\begin{array}{l}\text { Arithmetic } \\
\text { mean }^{\mathrm{a}}\end{array}$ & $95 \% \mathrm{Cl}^{\mathrm{a}}$ & $\begin{array}{c}\text { Arithmetic } \\
\text { mean }^{\mathrm{a}}\end{array}$ & $95 \% \mathrm{Cl}^{\mathrm{a}}$ \\
\hline $\begin{array}{l}\text { Injection workers } \\
\text { Tunnel workers }\end{array}$ & $\begin{array}{c}95.8^{\mathrm{a}} \\
104.2\end{array}$ & $\begin{array}{l}89.5-102 \\
101-107\end{array}$ & $\begin{array}{l}84.1^{1 b} \\
97.1^{b}\end{array}$ & $\begin{array}{l}76.7-91.6 \\
93.5-101\end{array}$ & $\begin{array}{l}85.2^{\mathrm{c}} \\
92.2^{2}\end{array}$ & $\begin{array}{l}80.9-89.5 \\
90.2-94.3\end{array}$ & $\begin{array}{l}68.6^{\mathrm{d}} \\
82.7^{2}\end{array}$ & $\begin{array}{l}57.1-80.3 \\
77.2-88.2\end{array}$ \\
\hline
\end{tabular}

a Mean and corresponding $95 \% \mathrm{Cl}$ adjusted for years in the same job and smoking status.

$P=0.01, P=0.002, P=0.003, P=0.03$ for the comparison between working groups in a 3-way analysis of variance model. 
was demonstrated to be associated with length of exposure (years in the same job) (OR 7.5, 95\% CI 1.3-45.2, for $<10$ years versus $>20$ years).

Toluene-diisocyanate-HSA-specific IgE antibodies were found in a RAST for $10.5 \%(2 / 19)$ of the injection workers and for none of the tunnel workers. The 2 TDIHSA-specific IgE positive injection workers complained about work-related symptoms of the respiratory tract. Formaldehyde- or diphenylmethane-4.4-diisocyanateHSA-specific IgE antibodies were not found.

The structured interviews showed that none of the tested workers had been informed about possible health hazards related to the use of the chemicals, nor did they report any use of airway protection. Several of the workers reported that they had suffered eye, nose, and throat irritation when burning or grinding off excesses of cured polyurethane, a common method used by the workers.

\section{Exposure assessment}

The exposure to the monomer MDI, recorded by personal sampling, was low in all the work operations, and mostly below the detection level $\left(<1 \mu \mathrm{g} / \mathrm{m}^{3}\right)$, in a total of 20 samples. The monomer MDI was detected on 2 occasions ( 1.9 and $3.0 \mu \mathrm{g} / \mathrm{m}^{3}$ ) by personal monitoring when isocyanate resin was spilled during injection work, but the values were also low. MDI was not detected in any other samples.

The concentrations of total prepolymer isocyanate showed substantial variation, varying from 5.5 to 300 (median 7.1) $\mu \mathrm{g} / \mathrm{m}^{3}$ for the shift samples $(\mathrm{N}=4)$ and from 18 to 4300 (median 103) $\mu \mathrm{m} / \mathrm{m}^{3}$ for short-term exposure $(\mathrm{N}=8)$. The highest value $\left(4300 \mu \mathrm{g} / \mathrm{m}^{3}\right)$ was found when cured polyurethane was being ground.

Six samples from the stationary sampling showed low concentrations: monomer MDI $<4 \mu \mathrm{g} / \mathrm{m}^{3}$ and prepolymer MDI varying from $<4 \mu \mathrm{g} / \mathrm{m}^{3}$ during injection work to 7.0 $\mu \mathrm{g} / \mathrm{m}^{3}$ during the mixing of reagents and $31.0 \mu \mathrm{g} / \mathrm{m}^{3}$ when isocyanate resins were spilled.

\section{Discussion}

The results of our study indicate that injection workers may have an increased risk of developing respiratory symptoms, airflow obstruction, and bronchial hyperreactivity when compared with other tunnel workers. The prevalence of respiratory symptoms was higher among both the injection workers and the tunnel workers than the prevalence reported in general population studies $(12$, 13), and among the injection workers it was even higher than reported for other work populations exposed to isocyanates (1), dust and fluorides (24), or western red cedar (25). The prevalence of abnormal methacholine hyperresponsiveness was also higher among the injection
Table 4. Prevalence of asthma, chronic obstructive lung disease and airflow limitation among the injection $(N=19)$ and tunnel ( $\mathrm{N}=104)$ workers. $(95 \% \mathrm{Cl}=$ confidence interval)

\begin{tabular}{|c|c|c|c|c|}
\hline \multirow[t]{2}{*}{ Diagnosis } & \multicolumn{2}{|c|}{ Prevalence } & \multirow{2}{*}{$\begin{array}{l}\text { odds } \\
\text { ratio }\end{array}$} & \multirow[t]{2}{*}{$95 \% \mathrm{Cl}$} \\
\hline & $\begin{array}{l}\text { Injection } \\
\text { workers } \\
\text { (N) }\end{array}$ & $\begin{array}{c}\text { Tunne! } \\
\text { workers } \\
\text { (N) }\end{array}$ & & \\
\hline Asthma & 5 & 1 & 34.6 & $3.6-334.0$ \\
\hline Chronic obstructive lung disease & 7 & 10 & 4.5 & $1.3-15.3$ \\
\hline Airflow limitation & 7 & 4 & 14.5 & $3.1-66.9$ \\
\hline
\end{tabular}

a Odds ratio adjusted for years in the same job and smoking status by logistic regression.

workers $(37 \%)$ than among the other tunnel workers $(14 \%)$, as well as being higher than values determined in general population studies $(12,13)$ and among aluminium and western red cedar workers $(24,25)$.

The prevalence of asthma (26\%) among the injection workers was high. Although the incidence varies widely depending on the form of diisocyanate and type of manufacture or use, it is generally accepted that approximately $5-10 \%$ of exposed workers develop occupational asthma after exposure to TDI, the most widely studied of the diisocyanates $(26,27)$. Estimates as high as $15 \%$ have been proposed (28). In all cases, the estimates may be low due to selection by sensitized workers leaving the industry and the difficulty of diagnosing the disease.

Exposure of injection workers to isocyanates liberated from uncured prepolymer isocyanates and cured polyurethane resins has been demonstrated at relatively high levels when compared with occupational exposure limits for MDI $\left(50 \mu \mathrm{g} / \mathrm{m}^{3}\right.$, Norway 1998). Through the structured interview we learned that it has been common to burn off excess polyurethane foam. It is probably the work operation that has given the highest exposure. We found it unethical to let the injection workers repeat this practice in order to assess exposure. Thus the exposure level was probably underestimated. The exposure assessment showed, however, that the injection workers were exposed to relatively high levels of isocyanates when grinding cured polyurethane, which is still a common work operation. In 1 investigation among car painters it was found that exposure to high concentrations of airborne MDI prepolymers induced asthma at the same or greater frequency in exposed workers when compared with workers exposed to isocyanate monomers (29). The dose and length of exposure to diisocyanates necessary to induce asthma are not known, but it has been suggested that the frequency of intermittent peaks in the exposure may be more important than time-weighted averages (4).

Agents other than isocyanates could have contributed to the health effects. In case reports acrylic resins have been assumed to cause effects on the airways $(10,11)$. 
The resins were, however, methyl methacrylate- and cyanoacrylate-based, not methylolacrylamide, the actual monomer in our study. We did not find any evidence in the literature that exposure to methylolacrylamide causes airway disease. Therefore acrylamide was not considered further in the exposure assessment. Finally the injection workers are exposed to inorganic gases and respirable dust (3) from blasting and diesel exhausts just as other tunnel workers are. Experimental human exposures to diesel exhausts show that lung inflammatory and other cellular effects can occur after single exposures, and sparse data suggest that occupational exposures might affect respiratory function and symptoms (30).

\section{Concluding remarks}

We conclude that tunnel workers, working with injection chemicals such as isocyanate-based and acrylamidebased resins, have a significantly higher prevalence of respiratory symptoms, methacholine hyperresponsiveness, asthma, and airflow limitation than other heavy construction workers working in tunnels. Exposure to decomposed MDI is relatively high when compared with the occupational exposure limits for TDI and MDI monomer (35 and $50 \mu \mathrm{g} / \mathrm{m}^{3}$, respectively, both being timeweighted averages, Norway 1998). Monomers were only occasionally found, but exposure assessment, for example, by heating, was not done. Thus exposure to decomposed polyurethane seems to cause respiratory symptoms and disease, at least in tunnel work.

\section{Acknowledgments}

We thank the injection and tunnel workers for participating in our study. Nycomed Pharma AS, Oslo, Norway, carried out the allergy screening with Phadiatop and the RAST on toluene-diisocyanate-HSA, diphenylmethane-4.4-diisocyanate-HSA and formaldehyde-HSA. The Miljø-kjemi Norwegian Environmental Centre AS carried out the sampling and the analyses of monomer and prepolymer MDI. We thank Professor Tor Norseth, Dr Wijnand Eduard, and Dr Helge Kjuus, from the National Institute of Occupational Health, Oslo, Norway, for their valuable advice during the preparation of the manuscript.

The project received financial support from the Working Environment Fund of the Confederation of Norwegian Business and Industry. The study was approved by The Data Inspectorate and the Regional Medical Ethics Board.

\section{References}

1. Schwartz DA, Baker EL. Respiratory illness in the construction industry: airflow obstruction among painters. Chest 1988;92:134-37.

2. Meadway J. Asthma and atopy in workers with an epoxy adhesive. Br J Dis Chest 1980;74:149—54.

3. Ulvestad B, Melbostad E. Airways symptoms, lung function and bronchial reactivity in tunnel workers. Oslo: National Institute of Occupational Health, 1992. HD 1028/92 BR. In Norwegian.

4. Musk AW, Peters JM, Wegman DH. Isocyanates and respiratory disease: current status. Am J Ind Med 1988;13:331-49.

5. Wegman DH, Peters JM, Pagnotto L, Fine LJ. Chronic pulmonary function loss from exposure to toluene diisocyanate. Br J Ind Med 1977;34:196-200.

6. Zeiss R. Occupational lung disease induced by reactive chemicals. Clin Rev Allergy 1985;3:217-26.

7. Baur X. Hypersensitivity pneumonitis (extrinsic allergic alveolitis) induced by isocyanates. J Allergy Clin Immunol 1995;95:1004-10.

8. Littorin M, Truedsson L, Welinder H, Skarping G, Mårtensson U, Sjøholm AG. Acute respiratory disorder, rhinoconjunctivitis and fever associated with the pyrolysis of polyurethane derived from diphenylmethane diisocyanate [case report]. Scand J Work Environ Health 1994;20:216-22.

9. Baur X, Marek W, Ammon J, Czuppon AB, Marczynski B, Raulf-Heimsoth $M$, et al. Respiratory and other hazards of isocyanates. Int Arch Occup Environ Health 1994;66:14152.

10. Lozewicz S, Davison AG, Hopkirk A, Burge PS, Boldy D, Riordan JF, et al. Occupational asthma due to methyl methacrylate and cyanoacrylates. Thorax 1985;40:836-39.

11. Kennes B, Garcia-Herreros P, Dierckx P. Asthma from plexiglas powders. Clin Allergy 1981;11:49-54.

12. Burney PGJ, Britton JR, Chinn S, Tattersfield AE, Papacosta $\mathrm{AO}$, Kelson MS, et al. Descriptive epidemiology of bronchial reactivity in an adult population: results from a community study. Thorax 1987;42:38-44.

13. Woolcock AJ, Peat JK, Salome CM, Yan K, Anderson SD, Schoeffel RE, et al. Prevalence of bronchial hyperresponsiveness and asthma in a rural adult population. Thorax 1987;42:361-68.

14. Boushey HA, Holtzman MJ, Sheller JR, Nadel JA. Bronchial hyperreactivity. Am Rev Respir Dis 1980;126:389-413.

15. American Thoracic Society. Standardisation of spirometry1987 update. Am Rev Respir Dis 1987;136:1285-98.

16. Gulsvik A. Obstructive lung disease in an urban population [thesis]. Oslo: Reprografisk Industri A/S, 1979.

17. Cockroft DW. Bronchial inhalation tests: measurement of nonallergic bronchial responsiveness. Ann Allergy 1985;55:52738.

18. Eriksson NE. Allergy screening with Phadiatop and CAP Phadiatop in combination with a questionnaire in adults with asthma and rhinitis. Allergy 1990;45:285-92.

19. Bakke P, Baste V, Hanoa R, Gulsvik A. Prevalence of obstructive lung disease in a general population: relation to occupational title and exposure to some airborne agents. Tho$\operatorname{rax} 1991 ; 46: 863-70$.

20. Gulsvik A. Prevalence and manifestations of obstructive lung disease in the city of Oslo. Scand J Respir Dis 1979;60:28696.

21. Health and Safety Executive, Occupational Medicine and Hy- 
giene Laboratory. Organic isocyanates in air. Sheffield: Health and Safety Executive, Occupational Medicine and Hygiene Laboratory, 1994. Method for the Determination of Hazardous Substances (MDHS 25/2).

22. Hosmer DW, Lemeshow S. Applied logistic regression. New York (NY): John Wiley, 1989.

23. Box GEP, Hunter WG, Hunter JS. Statistics for experimenters. New York (NY): John Wiley 1978.

24. Kongerud J, Scyseth V. Methacholine responsiveness, respiratory symptoms and pulmonary function in aluminium potroom workers Eur Respir J 1991;4:159—66.

25. Vedal S, Chan-Yeung M, Enarson DA, Chan H, Dorken E, Tse KS. Plicatic acid specific IgE and non-specific bronchial hyperresponsiveness in western red cedar workers. J Allergy Clin Immunol 1986;78:1103-9.

26. Diem JE, Jones RN, Hendrick DJ, Glindmeyer HW, Dharmarajan V, Butcher BT, et al. Five years longitudinal study of workers employed in a new toluene diisocyanate manufactur- ing plant. Am Rev Respir Dis 1982;126:420—8.

27. Butcher BT, Jones RN, O'Neil CE, Glindmeyer HW, Diem JE, Dharmarajan V, et al. Longitudinal study of workers employed in the manufacture of toluene diisocyanate. Am Rev Respir Dis 1977;116:411.

28. Peters JM, Wegman DH. Epidemiology and toluene diisocyanate (TDI) induced respiratory disease. Environ Health Perspect 1975:97-100.

29. Seguin P, Allard A, Cartier A, Malo JL. Prevalence of occupational asthma in spray painters exposed to several types of isocyanates, including polymethylene polyphenylisocyanate. J Occup Med 1987;29:30-44.

30. Mauderly JL. Toxicological and epidemiologic evidence for health risks from inhaled engine emissions. Environ Health Perspect 1994;102:165-71.

Received for publication: 4 September 1998 